\title{
SUCCESSFUL MANAGEMENT OF CORNEAL ULCER USING THIRD EYELID FLAP TECHNIQUE IN AN ASSAM HILL GOAT - A CASE REPORT
}

\author{
N. AHMED*, M. P. BAISHYA, B. K. SARMA, S. N. YADAV \\ P. K. BORO, P. THAKURIA AND D. PAUL \\ Veterinary Clinical Complex \\ Lakhimpur College of Veterinary Science \\ Assam Agricultural University, Joyhing - 787051 \\ North Lakhimpur, Assam, India
}

\begin{abstract}
A four year old female Assam Hill goat was presented with profuse lacrimal discharge, corneal opaqueness and vision loss of the left eye. Detailed clinical examination revealed presence of ulcer and opacity over the corneal. The affected eye was managed with third eyelid flap technique. The goat was recovered uneventfully.
\end{abstract}

Key words: Assam Hill goat, Corneal opacity, Corneal ulcer, Management, Third eyelid flap

Corneal ulcer is an inflammatory or more seriously, infective condition of the cornea involving disruption of its epithelial layer with involvement of the corneal stroma. In animals, corneal ulcer occurs due to variety of causes, including eye diseases (entropion, ectropion, large eyelid openings, extra eyelashes, ectopic cilia, 
infection), dry eye, exposure keratitis, physical and chemical trauma (Stanley, 2007). Corneal ulcers are common in canine and equine but uncommon in caprine (Slatter and Dietrich, 2003). The challenge in repairing the ulcerated cornea results from inherent lack of elasticity of corneal tissue (Macsai, 2011). Hence, selection of proper management technique is very necessary as it may permanently damage the vision. In this context, this article represents the successful management of corneal ulcer with opacity by applying third eyelid flap technique in an Assam Hill goat.

A four years old female Assam Hill goat was presented in the Veterinary Clinical Complex, Lakhimpur College of Veterinary Science, Assam Agricultural University, North Lakhimpur, Assam, India with profuse lacrimal discharge (Fig. 1), corneal opaqueness and loss of vision of the left eye. On clinical examination, the goat was found dull and depressed; and visual examination revealed macroscopic corneal ulcer along with opacity in the left eye (Fig. 2 ). However, the right eye was normal. The body condition of the goat was poor, however body temperature, pulse rate and respiration rate were recorded as normal. A sterile swab was collected from the ulcerated area of the affected eye and sent for microbiological culture, isolation and identification.Microbiological investigation revealed the growth of Staphylococcus aureus.

Preoperatively, the affected eye was cleaned with normal saline solution and applied with $0.5 \%$ povidone iodine over the ulcerated part. Under auriculopalpebral nerve block with $2 \%$ lignocaine hydrochloride, third eyelid flap technique was carried out by grasping the third eyelid from its anterior border and pulled across the globe up to fornix near lateral canthus where it was sutured with skin (Fig. 3). Then tarsorrhaphy has been performed in the affected eye to prevent damage to the third eyelid by self mutilation (Fig. 4). A small space was left at medial and lateral canthus for medication. Postoperatively, the goat was treated with parenteral antibiotic viz. gentamicin $(0.25 \mathrm{~mL}$; subconjunctival), flunixin meglumine $(2 \mathrm{mg} /$ $\mathrm{kg} \mathrm{b}$. wt.; i/m) for seven days and vitamin A (1 Lakh IU; i/m) week interval for 3 consecutive occasions. After a week, the suture was removed and Fluorescein dye retention technique revealed the corneal ulcer had completely healed but corneal opacity was still present (Fig. 5). The pupillary light reflex revealed the goat had gained partial vision. As the corneal ulcer healed completely, the goat as further treated with antibiotic plus corticosteroid eye drop (ciprofloxacin and dexamethasone; 2 drops) thrice daily (every 
Indian Journal of Animal Health, June, 2019

\section{Management of corneal ulcer using third eyelid flap technique}

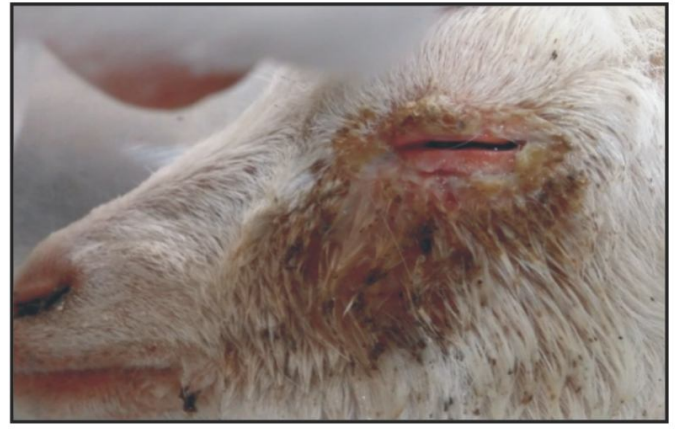

Fig. 1. Photograph showing profuse lacrimal discharge

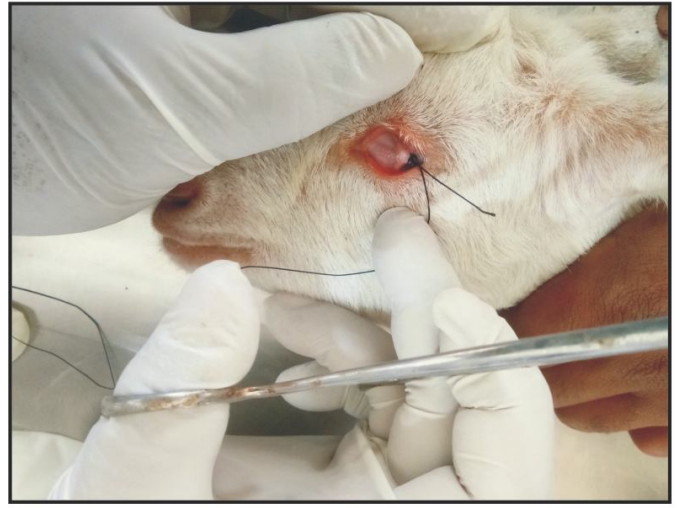

Fig. 3. Photograph showing third eyelid flap

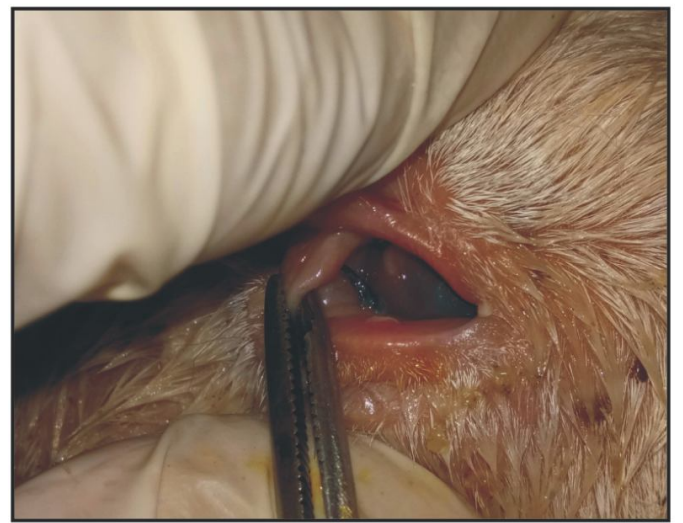

Fig. 5. Photograph showing healed corneal ulcer with persistent opacity

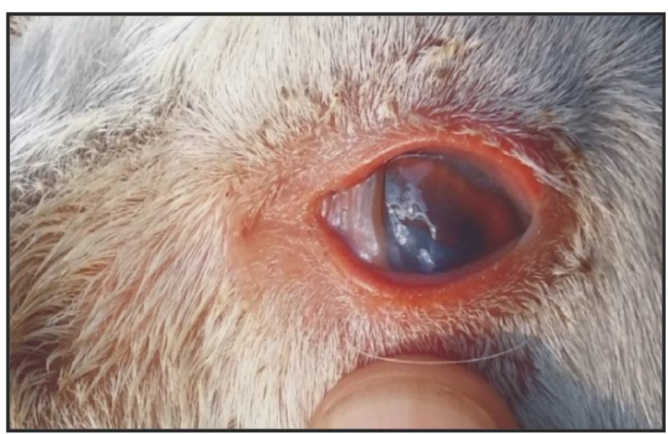

Fig. 2. Photograph showing corneal ulcer with opacity

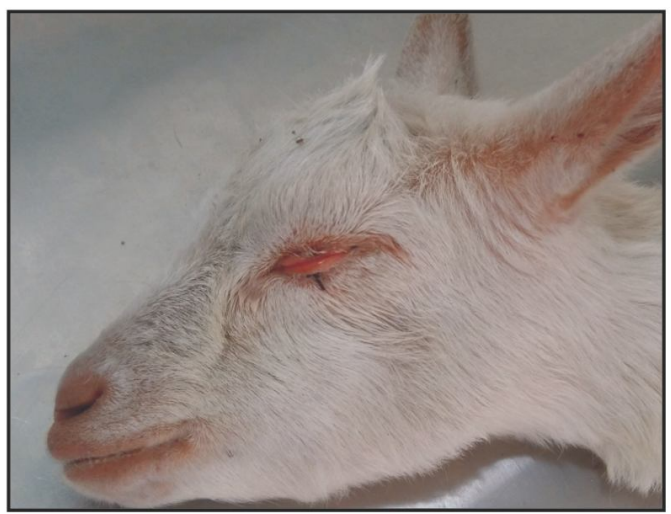

Fig. 4. Photograph showing tarsorrhaphy in the affected eye

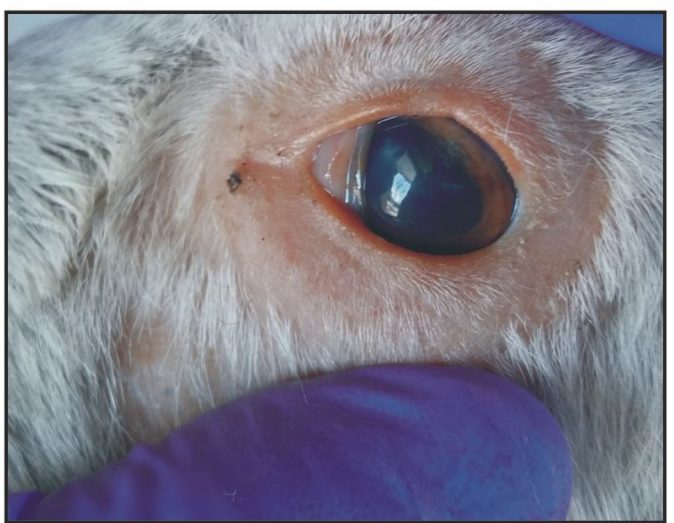

Fig. 6. Photograph showing completely recovered eye 
8 hours interval) along with vitamin A injection for next 14 days. The goat was recovered uneventfully (Fig. 6).

Blunt or sharp trauma usually causes globe rupture along the limbus rather than dissecting across central cornea (Slatter and Dietrich, 2003). In the present case, the corneal ulcer was managed with third eyelid flap technique which was in concurrence with the reports of early researches in horse (Jhala et al., 2012). In contrast to the present case, early researchers opined that third eyelid flaps could be used to protect and support/reinforce the weakened cornea, but contraindicated in infected ulcers (Turner, 2008). Staphylococcus aureus has been isolated from the swab collected from the ulcerated cornea. S. aureus is the normal inhabitant of skin, other parts of the body and environment or may act as an opportunistic pathogen which may not be the actual cause of corneal ulcer. Antibiotic plus corticosteroid

\section{REFERENCES}

Fowler ME and Mikota SK, 2008. Biology, medicine, and surgery of elephants. John Wiley and Sons, pp 446

Jhala SK, Joy N, Dar MUD, Tiwari DK, Patil DB et al., 2012. Management of eye drops was used to subside the corneal opacity as it suppresses inflammation and secondary bacterial infections respectively. Moreover, corticosteroid medication reduces corneal opacification by inhibiting fibroplasias and decreasing vascularization. Concurrently, vitamin A treatment helps in the repairmen of damage part of the cornea along with improvement of vision (Fowler and Mikota, 2008).

Corneal ulcer is a serious condition in livestock which may cause temporary to permanent eye damage and it needs immediate attention. We suggest prompt presentation and proper treatment of animals affected with corneal ulcer.

\section{ACKNOWLEDGEMENT}

All authors are grateful to the Associate Dean, Lakhimpur College of Veterinary Science, AAU, North Lakhimpur, Assam for his kind supports. corneal ulcer using third eyelid flap technique in a horse. Indian J Vet Surg, 33(1): 73

Macsai MS, 2011. Surgical Management and Rehabilitation of Anterior Segment 
Trauma. In: Cornea. Ed. Krachmer JH, Mannis, JM and Holland EJ, 3rd edn., Mosby, Elsevier Inc, pp 1655-1669

Slatter D and Dietrich U, 2003. Cornea and Sclera. In: Textbook of Small Animal Surgery. Ed. Slatter, D, 3rd edn., W. B. Saunders, Philadelphia, pp 13681396
Stanley RG, 2007. Management of corneal ulcers in small animals. World small animal veterinary association world congress proceedings, East Makvern, Australia

Turner SM, 2008. Small Animal Ophthalmology. In: Saunders Solutions in Veterinary Practice, Saunders Elsevier, London, pp 130-131 